\title{
MATERNIDAD SUBROGADA UNA MIRADA A SU REgULACIÓN EN MÉXICO
}

\author{
SurRogacy: A LOOK AT ITS \\ Regulation in Mexico
}

\author{
Maternidade de SUb-ROgaÇÃo: \\ UM OLHAR NA SUA REGULAÇÃO NO \\ MÉXICO
}

VERÓNICA LIDIA MARTÍNEZ-MARTÍNEZ*

RECIBIDO: 15 DE ENERO DE 2015. ENVÍO A PARES: 18 DE MARZO DE 2015 APROBADO POR PARES: 23 DE JUNIO DE 2015. ACEPTADO: 30 DE JUNIO DE 2015

DOI: $10.5294 / D I K A .2015 .24 .2 .7$

PARA CITAR ESTE ARTÍCULO / TO REFERENCE THIS ARTICLE / PARA CITAR ESTE ARTIGO MARTínEZ-MARTíneZ, VERÓNICA LIDIA, "MATERNIDAD SUBROgAdA. UNA MIRAdA A SU REGULACIÓN EN MÉXICO”, EN DIKAION, 24-2 (2015), PP. 353-382. 


\section{RESUMEN}

El presente trabajo aborda el tema de la maternidad subrogada en México, a partir de sus antecedentes, marco conceptual y modalidades, pues estos constituyen las herramientas que nos permitirán comprender la heterogénea regulación expedida para legislar esta técnica de reproducción asistida, cuya problemática se expone en estas líneas.

\section{PALABRAS CLAVE}

Maternidad subrogada; madre subrogada; reproducción asistida; derechos reproductivos; contrato de subrogación. 


\section{ABSTRACT}

This paper addresses the issue of surrogacy in Mexico, based on its background, conceptual framework and the varieties of surrogacy. These are the tools that allow us to understand the heterogeneous regulations that have been issued to legislate on this assisted reproductive technique, the problems of which are outline in this work.

\section{KEYWORDS}

Surrogacy; surrogate; assisted reproduction; reproductive rights; surrogacy contract. 


\section{RESUMO}

Este trabalho aborda o tema da maternidade de sub-rogação no México a partir de seus antecedentes, referencial conceitual e modalidades, visto que estes constituem as ferramentas que permitirão compreender a heterogênea regulação expedida para legislar essa técnica de reprodução assistida, cuja problemática é exposta nestas linhas.

\section{PALAVRAS-CHAVE}

Maternidade de sub-rogação; mãe sub-rogada; reprodução assistida; direitos reprodutivos; contrato de sub-rogação. 
SUMARIO: INTRODUCCIÓN; 1. ANTECEDENTES; 2. CONCEPTUALIZACIONES Y MOdALIDADES; 3. MÉXICO ANTE LA MATERNIDAD SUbrogada; 3.1. QUerÉTARO; 3.2. TABASCO; 3.3. CIUdAd de MÉxico; 3.4. Sinaloa; 3.5. Coahuila; 3.6. Otros estados; 4. Problemática JURÍDICA; 5. CONCLUSIÓN; BIBLIOGRAFÍA.

\section{INTRODUCCIÓN}

A pesar de los innumerables ataques de los que ha sido presa la denominada maternidad subrogada, actualmente es uno de los métodos de reproducción asistida que se practica no solo en países en los que se encuentra legalizado su ejercicio, sino en los que se ha satanizado, al considerar que atenta contra la dignidad del ser humano y favorece el abandono, el tráfico y la venta de menores.

El denominado alquiler de útero ha evidenciado el retraso que existe en el ámbito jurídico respecto a la regulación de su práctica y de sus efectos que impactan no solo en la esfera íntima de las personas que recuren a ella, sino trastocan el terreno público, derrumbándose la infranqueable dicotomía entre lo público y lo privado, de la cual diera cuenta Bobbio en su magistral obra Estado, gobierno y sociedad.

A partir de los antecedentes de la maternidad subrogada y de su aparato conceptual, que nos auxilian para entender esta revolucionaria forma de "crear vida", la presente obra - siguiendo el principio de jerarquía normativa consagrada en el artículo 133 constitucional-analiza la forma en que México ha regulado el comúnmente denominado alquiler de vientre y los problemas jurídicos que enfrenta ante la disimilitud y deficiencia de sus ordenamientos jurídicos.

\section{Antecedentes}

El origen de la maternidad subrogada es un tema controversial, pues se sostiene que esta data desde la Antigüedad. El Código del rey Hammurabi —creado en Mesopotamia en 1780 a. C.- disponía que la mujer estéril que quería tener hijos debía dar una esclava a su marido con fines de procreación (Ley 146), perdiendo asi el marido todo derecho a repudiar a su esposa. Si la esclava no daba hijos del esposo a su ama, esta podía venderla (Ley 147). Cuando la esclava proporcionada por la mujer daba hijos al señor, no podía este último tomar concubina (Ley 144). Si la mujer principal no daba hijos a su marido, ni le proporcionaba esclava para tenerlos, el marido podía tomar una concubina y recibirla en su casa como esposa, pero no de la misma categoría que la mujer principal (Ley 145). ${ }^{1}$

En la India, de acuerdo con las leyes de Manú, la religión prescribía que la mujer estéril se reemplazara al cabo de ocho años. ${ }^{2}$ Entre los hebreos, en el Génesis se relata que Sarah —al ser estéril— dio a su marido Abraham por mujer a su sierva

1 Federico Lara Peinado, Código de Hammurabi, Madrid, Editora Nacional, 1982, p. 107.

2 Leyes de Manú, IX, 81, citadas en Fustel de Coulanges, La ciudad antigua, 9 ed., México, Porrúa, 1994 , p. 33. 
egipcia, Agar. ${ }^{3}$ De igual forma, se da cuenta de la utilización que Raquel hacía de su esclava Bilhá para tener un hijo de Jacob. ${ }^{4}$

Por su parte, la antigua religión de griegos y romanos disponía que si un matrimonio resultaba estéril por causa del marido, entonces un hermano o un pariente de este último debía sustituirlo y la mujer tenía que entregarse a ese hombre. El hijo que nacía de esa unión se consideraba como del marido y continuaba su culto. ${ }^{5}$ En el caso del pueblo de los Kgatla —en el sur de África-, cuando una pareja no podia tener hijos, le era permitido encargar su próximo hijo a una mujer fértil. ${ }^{6}$

Desde la posición contraria, en cambio, se afirma que los antecedentes de la maternidad subrogada datan del siglo XX. Sobresaliendo en 1940 el primer banco de semen, ${ }^{7}$ y para 1944 tiene lugar la práctica de la primera fecundación extracorpórea de embriones humanos, ${ }^{8}$ realizada por los biólogos John Rock y Meneen. ${ }^{9}$

Asimismo, en 1953 en Estados Unidos, se presentan los primeros embarazos con semen congelado. ${ }^{10}$ Durante 1969 se practicó una fertilización in vitro de gametos humanos en Reino Unido y en 1975, a través de un anuncio publicado en un periódico de California, una pareja infecunda solicitaba una mujer para ser inseminada artificialmente. ${ }^{11}$ Esta publicación y las que siguieron favorecieron la creación de las sociedades de préstamos de úteros, siendo las pioneras la Surrogate Family Service Inc, que concretó en 1976 el primer acuerdo de maternidad subrogada a través de una inseminación artificial, financiada por el abogado Noel Keane, así como la Surrogate Parenting Associates —que desde su fundación en 1979 por Richard Levine, en Luisville (Kentucky) - tenía como misión la celebración de contratos de subrogacía.

Paradigmáticos han sido los casos de Louise Brown, concebida fuera del útero materno mediante la fecundación de un óvulo proporcionado por la madre, Lesley Brown, así como el conocido caso de Baby Cotton, nacido en Londres el 4 de ene-

Génesis, 16.1.

$4 \quad$ Ibid., 30.3.

5 Fustel DE Coulanges, La ciudad antigua, op. cit., nota 2, p. 33.

6 Rosario Esteinou, La nueva generación social de familias. Tecnologías de reproducción asistida y temas contemporáneos, México, Publicaciones de la Casa Chata, 2012, p. 153.

7 Ingrid Brena Sesma, "Algunas consideraciones en torno al derecho a la reproducción por medio de inseminación artificial”, en Boletín Mexicano de Derecho Comparado, México, nueva serie, XXVIII, 82 (enero-abril de 1995), p. 72.

8 Los primeros ensayos se realizaron con vegetales, después con animales. Se tiene noticias de que en el siglo XIV, los árabes utilizaban la inseminación artificial para adulterar la estirpe de los caballos de sus enemigos. Véase Aníbal Guzmán Ávalos, Inseminación artificial y fecundación in vitro humanas. Un nuevo modo de filiación, México, Universidad Veracruzana, 2001, pp. 27-28.

9 Dolores Loyarte y Adriana Rotonda, Procreación humana artificial; un desafio bioético, Buenos Aires, Depalma, 1995, p. 115.

358 María CARCABA FERnÁndez, Los problemas jurídicos planteados por las nuevas técnicas de procreación, España, Bosch, 1995, p. 14.

11 Jaime VidAL MARTÍNEz, Las nuevas formas de reproducción humana. Estudio desde la perspectiva del derecho civil español, Madrid, 1988, p. 180. 
ro de 1984, quien fuera gestado por una mujer inglesa por encargo de una pareja estadounidense a cambio de una suma de dinero. ${ }^{12}$

De igual importancia resulta en 1989 la celebración del contrato de gestación subrogada $^{13}$ entre el matrimonio Whitehead y el señor Stern, cuya nulidad, a pesar de haber sido decretada por la Suprema Corte de New Jersey, ante el reconocimiento de la maternidad de la señora Mary Beth Whitehead, determinó entregar la custodia de la menor al padre biológico, William Stern. ${ }^{14}$

En un sentido opuesto, sobresalen los contratos de maternidad subrogada concertados entre la señora Anna Johnson y el matrimonio Calvert, así como el celebrado entre la señora Johnson y el matrimonio Mosqueta, en los que se privó de derechos maternos a las mujeres gestantes al decretarse la validez de los contratos. ${ }^{15}$

La exposición de los anteriores casos evidencia las discrepancias que existen respecto al origen del alquiler de útero y la disimilitud de resoluciones pronunciadas por los órganos jurisdiccionales en lo concerniente a la filiación y custodia de los menores nacidos a través de este método de reproducción asistida, cuya práctica se ha hecho común como lo prueban los anuncios publicados en Internet y en los diarios, así como la existencia de las principales "industrias de la fertilidad" o del llamado turismo reproductivo, ubicados en la India, Ucrania, Grecia y California.

\section{CONCEPTUALIZACIONES Y MODALIDADES}

Equivocadamente se han utilizado como sinónimos los términos esterilidad e infertilidad, cuando desde el punto de vista médico, la esterilidad se refiere a la

12 Silvana María Chiapero, Maternidad subrogada. Esterilidad. Derecho a la procreación. Nuevas técnicas. Protección del embrión extracorpóreo. Filiación. El contrato de gestión por otro. Efectos de la nulidad, Argentina, Astrea, 2012, p. 49.

13 En este caso, conocido como "Baby $M$ ", el contrato disponía que el único propósito del acuerdo era procrear una criatura que estuviera biológicamente relacionada con el señor Stern; que la señora Whitehead renunciaría libremente y entregaría la criatura al señor Stern, luego del nacimiento, y concluiría todos sus derechos materno-filiales con la criatura; que el señor Whitehead reconocía que su esposa sería inseminada artificialmente y que este último y su esposa renunciarian a establecer relaciones paterno-filiales y derechos materno-filiales respectivamente. Se establecía además que el señor Whitehead impugnaría la presunción de paternidad de la criatura; que el señor Stern pagaria a la señora Whitehead una consideration (compensación por los servicios y gastos) además de aquellos gastos en que incurriese la señora Whitehead debido al estado de embarazo; que el señor Stern le pondría nombre a la criatura; que en caso de que el señor Stern muriera antes o después de nacer la criatura, esta sería entregada a la señora Whitehead, quien no abortaría la criatura concebida, salvo que su salud estuviera en riesgo o que la criatura concebida tuviera anomalías psicológicas. Véase Flavio Cumpiano Alfonso, “¿Bebés a la orden? Consideraciones éticojurídicas de la maternidad subrogada”, en Revista del Colegio de Abogados de Puerto Rico, Puerto Rico 56 (1) (enero-marzo de 1995), p. 79.

14 Hernán CoRRAl TAlCiani, "Maternidad subrogada: sobre la pretensión de formalizar la filiación perseguida mediante la adopción o la recepción de su práctica en el extranjero”, en Cristián LEPIN Molina (coord.), Técnicas de reproducción humana asistida. Desafios del siglo XXI: una mirada transdisciplinaria, Chile, AbeledoPerrot-Thomson Reuters, 2013, p. 86.

Ibid., p. 167. 
imposibilidad absoluta e irreversible de concebir, ${ }^{16}$ indica imposibilidad de efectuar la fecundación. ${ }^{17}$ Mientras que en la infertilidad femenina, la fecundación es posible, pero se trata de la patología propia de una mujer que no es capaz de lograr la viabilidad fetal ${ }^{18}$. Propiamente, consiste en la pérdida sucesiva y reiterada de embarazos, una vez que han sido logrados.

Cuando la esterilidad o la infertilidad no pueden ser resueltas por vía quirúrgica o a través de tratamientos farmacológicos, ${ }^{19}$ surge la posibilidad de recurrir a las técnicas de reproducción asistida que consisten en formas artificiales de aplicación científica y tecnológica (biotecnologia) que permiten la reproducción humana sin emplear la forma natural de procreación. ${ }^{20}$

En la actualidad, las técnicas de reproducción asistida se presentan, por lo menos, bajo las formas de inseminación artificial ${ }^{21}$ homóloga (IAH), ${ }^{22}$ heteróloga (IAD) e intraperitoneal (IAI), fecundación in vitro, fecundación con trasplantes de embriones (FIVTE), transferencia intrauterina de gametos (TIG), transferencia de cigotos (preembriones en los primeros estadios de la fecundación) a las trompas de Falopio (ZIFT), transferencia de embriones en las trompas de Falopio en estadios más avanzados de desarrollo (TET), la inyección intracitoplasmática (ICSI), la transferencia de pronúcleos a las trompas de Falopio (PROST), la colocación de ovocitos y espermatozoides en el útero (TOAST) y la maternidad subrogada.

De acuerdo con el Diccionario de la Lengua Española, subrogar es sinónimo de sustituir, que significa poner a una persona o cosa en lugar de otra. ${ }^{23}$ De ahí que maternidad subrogada no es una técnica de reproducción artificial, sino un acto voluntario $^{24}$ que se produce como consecuencia de la posibilidad de practicar una inseminación artificial o una fecundación in vitro, ${ }^{25}$ caracterizada por el empleo

16 Esther Farnós Amorós, Consentimiento a la reproducción asistida. Crisis de pareja y disposición de embriones, Barcelona, Atelier, 2011, p. 27.

17 Dolores LOYARTE y Adriana RotANDA, Procreación humana artificial; un desafio bioético, op. cit., nota 9, p. 83.

18 Miguel Ángel Soto LAmAdrid, Biogenética, filiación y delito. La fecundación artificial y la experimentación genética ante el derecho, Argentina, Astrea, 1990, p. 315.

19 Ibid., p. 316.

20 Marcelo Valdiviezo García, "La ingeniería genética y la maternidad asistida", en Revista Jurídica. Órgano Oficial del Colegio de Abogados de la Libertad, Perú, 134 (enero 1996-julio 1999), p. 141.

21 De acuerdo con Ingrid BREna Sesma, voz "Fertilización artificial", en Rosa María Álvarez DE LARA et al., Diccionario de derecho civil y de familia, México, Porrúa, 2004, p. 167, a la inseminación artificial, al ser una técnica para facilitar la fertilización real y no simulada, incorrectamente se le ha dado el calificativo de artificial.

22 La inseminación artificial homóloga es explicada por Carlos Lema, quien indica que se trata de la inseminación realizada con semen de un individuo de la misma especie que la inseminada, y la inseminación heteróloga se lleva a cabo con semen de una especie distinta. Véase Carlos Lema AÑón, Reproducción, poder y derecho. Ensayo filosófico-jurídico sobre las técnicas de reproducción asistida, Madrid, Trotta, 1999, p. 36.

23 Real Academia de la Lengua Española, Diccionario de la lengua española, en http://lema.rae.es/drae/ srv/search?id=hIh6tqjTwD=hlh6tqjTwDXX2HZmVhhU, fecha de consulta: 2 de diciembre de 2014.

36024 Flavio Cumpiano Alfonso, “¿Bebés a la orden? Consideraciones ético-jurídicas de la maternidad subrogada”, op. cit., nota 13, p. 78.

25 María CARCABA Fernández, Los problemas jurídicos planteados por las nuevas técnicas de procreación, op. cit., nota 10, p. 23. 
de otro vientre y no el de la que desea la reproducción debido a la práctica de una histerectomia, a la carencia congénita de ovarios o de útero (síndrome de Rokitanski), a anomalias en la matriz e incluso la presencia de una enfermedad grave que desaconseje el embarazo, o tratándose de personas solteras y parejas homosexuales. ${ }^{26}$

Atendiendo a la aportación de los gametos, ${ }^{27}$ la maternidad subrogada puede presentar las siguientes modalidades:

- Subrogación total, plena o tradicional. La mujer contratada es inseminada y aporta sus propios óvulos, pero después de la gestación y el parto ${ }^{28}$ entrega al producto de la concepción. Normalmente se insemina con el esperma del padre comitente, pero también puede ser el esperma de un donante. ${ }^{29}$

- Subrogación parcial o gestacional. Este método consistente en implantar los gametos en la madre subrogada mediante fertilización in vitro. Da lugar a que el óvulo pueda pertenecer a la madre comitente o a una donante, pero no a la gestante, mientras que el esperma puede ser aportado por el padre comitente o un donante. ${ }^{30}$

De acuerdo con tal fin, ${ }^{31}$ la gestación subrogada puede ser:

- Subrogación altruista. Se presenta cuando la madre gestadora acepta llevar a cargo el procedimiento de maternidad subrogada de manera gratuita, por lazos de amor, amistad o parentesco con la pareja contratante. ${ }^{32}$

- Subrogación onerosa. En esta modalidad la madre gestadora recibe de la pareja contratante una contraprestación por concluir el embarazo y entregar al producto de la concepción al nacer.

\section{MÉXICO ANTE LA MATERNIDAD SUBROgADA}

El derecho a la reproducción humana se encuentra reconocido en México como un derecho fundamental de la persona, en el artículo 4o. constitucional, en cuya parte conducente dispone que "toda persona tiene derecho a decidir de manera

26 En Québec, Victoria y España se reconoce la doble maternidad respecto de las parejas de mujeres casadas que recurren a las técnicas de reproducción asistida. Véase Esther Farnós Amorós, Consentimiento a la reproducción asistida. Crisis de pareja y disposición de embriones, op. cit., nota 16, pp. 113, 114-115.

27 Adriana Hernández Ramírez y José Luis Santiago Figueroa, "Ley de Maternidad Subrogada en el Distrito Federal”, en Boletín Mexicano de Derecho Comparado, México, nueva serie XLIV, 132 (septiembre-diciembre de 2011), p. 1341.

28 Idem.

29 Ricardo Ortiz Sánchez, "Gestación subrogada”, en Revista Jurídica de Puerto Rico, Puerto Rico 76 (4) (2007), p. 1200.

30 Idem.

31 Ibid., pp. 1341-1342.

32 Adriana Hernández Ramírez y José Luis Santiago Figueroa, "Ley de Maternidad Subrogada en el Distrito Federal”, op. cit., nota 27, p. 1341. 
libre, responsable e informada sobre el número y el espaciamiento de sus hijos...”. Invocan este precepto quienes, en afán de dar continuidad a su genética, acuden a las modernas técnicas científicas que les ofrecen la oportunidad de tener descendencia, en vez de adoptar niños que les son ajenos.

A la disposición constitucional se adiciona el Programa de Acción de la Conferencia Internacional sobre Población y Desarrollo (CIPD) firmado por México, en el que se establece que los derechos reproductivos se basan en el reconocimiento del derecho básico de todas las parejas e individuos a decidir libre y responsablemente el número de hijos, el espaciamiento de los nacimientos, el intervalo entre estos y a disponer de la información y los medios para ello, así como el derecho a alcanzar el nivel más elevado de salud sexual y reproductiva. El mismo programa, en el Capítulo VII, denominado de los Derechos Reproductivos y Salud Reproductiva, punto 7.3, consagra el derecho a adoptar decisiones relativas a la reproducción sin sufrir discriminación, coacciones ni violencia, de conformidad con lo establecido en los documentos de derechos humanos. ${ }^{33}$

Es de destacarse que ni la Ley General de Salud ni su Reglamento en Materia de Investigación para la Salud hacen referencia alguna a la maternidad subrogada. Ambos ordenamientos solo se refieren en forma general a la inseminación artificial y a la fertilización in vitro.

Debido a que los estados de la República Mexicana y la Ciudad de México tienen competencia para legislar en materia de derecho de familia, en este apartado nos avocaremos a estudiar la normatividad de aquellas entidades federativas que prohíben o regulan - con serias deficiencias- a este método de reproducción asistida.

\subsection{Querétaro}

En primer lugar, el artículo 22 del Código Civil del estado de Querétaro dispone que la capacidad jurídica de las personas físicas se adquiere por el nacimiento y se pierde por la muerte, pero desde el momento que un individuo es concebido de manera natural o por medio de las técnicas de reproducción asistida, queda bajo la protección de la ley y se le tiene por nacido para los efectos declarados en el mismo Código. ${ }^{34}$

A la anterior protección, el citado precepto legal adiciona el reconocimiento del derecho que tiene la persona mayor de edad, de conocer la identidad de sus padres biológicos, cuando haya sido producto de una inseminación artificial o procreación asistida con contribución de donante o donantes. El mismo derecho le asiste a la persona concebida a través de estos métodos que haya sido posteriormente un.org/popin/icpd/conference/offspa/sconf13.html, fecha de consulta: 12 de diciembre de 2014.

34 Código Civil del estado de Querétaro, en http://www.legislaturaqueretaro.gob.mx/repositorios/ 10. pdf, fecha de consulta: 22 de diciembre de 2014 . 
adoptada, ${ }^{35}$ omitiéndose reconocer a los donantes el derecho de conocer a los hijos nacidos a través de las tecnologías reproductivas.

En lo concerniente al tema de la filiación, de acuerdo con la fracción III del artículo 312 del Código Civil del Estado de Querétaro, se establece que los hijos nacidos como producto de la aplicación de las técnicas de reproducción asistida se presumen hijos de los cónyuges, siempre y cuando no haya sido revocado el consentimiento para ello. Existe la presunción de revocación del consentimiento por la simple disolución del vínculo matrimonial, salvo que ambas partes reconozcan como hijo de matrimonio al producto derivado de la aplicación de las técnicas de reproducción asistida. ${ }^{36}$

Cabe señalar que al permitirse en el estado de Querétaro la adopción de embriones se prohíbe a las parejas adoptantes recurrir a la maternidad asistida o subrogada así como contratar el vientre de una tercera mujer para la gestación del embrión. ${ }^{37}$

\subsection{Tabasco}

Por su parte, el Código Civil para el Estado de Tabasco - uno de los pioneros en reconocer a las técnicas de reproducción asistida como una posible solución cuando la mujer es incapaz de concebir o de gestar debido a causas físicas o psicológicas- distingue a la madre gestante sustituta, de la madre subrogada y de la madre contratante.

La primera de las figuras jurídicas, es decir, la madre gestante sustituta es aquella mujer que lleva el embarazo a término y proporciona el componente para la gestación, pero no el componente genético. Por su parte, la madre subrogada provee el material genético y el gestante para la reproducción. La madre contratante es aquella mujer que convenga en utilizar los servicios de la madre gestante sustituta o de la madre subrogada, según sea el caso. ${ }^{38}$

La práctica en Tabasco permite que el contrato sea de carácter gratuito u oneroso. Respecto a este último punto encontramos que existe cierta aceptabilidad por la celebración del contrato de maternidad subrogada gratuito - contrato benévolo o con fines altruistas-, siempre que la mujer que admita ceder temporalmente su cuerpo otorgue su libre e informado consentimiento, al igual que su marido, si fuere casada. La mayoría rechaza el acuerdo oneroso de alquiler de útero, al equiparlo a un contrato de venta futura de hijo, prohibido por las legislaciones de los países y por los tratados internacionales, pues atenta contra la dignidad del

35 Ibid., artículo 404 del Código Civil del estado de Querétaro.

36 Ibid., artículo 312 del Código Civil del estado de Querétaro.

37 Ibid., artículo 400 del Código Civil del estado de Guerétaro.

38 Penúltimo párrafo del artículo 92 del Código Civil para el estado de Tabasco, en http://www. congresotabasco.gob.mx/LX/trabajo_legislativo/pdfs/codigos/Codigo_Civil_Tabasco.pdf, fecha de consulta: 23 de diciembre de 2014. 
ser humano, lo que significa que la persona no tiene precio y no puede ser considerada, bajo ninguna condición, como un simple instrumento. Ella excluye toda comercialización aunque sea parcial del cuerpo humano. ${ }^{39}$

Tratándose del padre, el Código Civil de Tabasco otorga especial importancia a la voluntad de procrear, al grado de establecerse en la fracción XVIII del artículo 272 de este ordenamiento, como una causal de divorcio necesario el empleo, por parte de la mujer, de los métodos de concepción humana artificial, sin el consentimiento del marido. ${ }^{40} \mathrm{El}$ marido no podrá desconocer a los hijos nacidos como resultado del empleo de alguno de los métodos de reproducción artificial, si consta de manera fehaciente su consentimiento. ${ }^{41}$

Finalmente, en el texto legal tabasqueño, se dispone que salvo el caso de que se trate de un hijo nacido de una madre gestante sustituta ${ }^{42}$ o como resultado de un contrato de maternidad sustituta, ${ }^{43}$ cuando el hijo nazca de una mujer casada que viva con su esposo, el Oficial del Registro Civil no podrá asentar como padre a otro que no sea el mismo marido, excepto que este haya desconocido al hijo y exista sentencia ejecutoria que así lo declare. Los dos casos de excepción consideramos que obedecen a que el Código Civil de Tabasco reputa como madre legal del niño a la que contrata los servicios de la gestante, abandonando la madre portadora toda pretensión de maternidad, cuando se produce el nacimiento del menor.

\subsection{Ciudad de México}

En el caso del Código Civil, para la Ciudad de México se reconoce en su artículo 162 el derecho que tienen los cónyuges a decidir de manera libre, informada y responsable el número y espaciamiento de sus hijos, así como a emplear, en los términos que señala el mismo ordenamiento, cualquier método de reproducción asistida para lograr su propia descendencia. ${ }^{44}$

Un aspecto por considerar del citado artículo 162, es que al permitir "cualquier método de reproducción asistida", deja abierta la posibilidad para que cónyuges y, por extensión, concubinos - al serles aplicables todos los derechos y obligaciones inherentes a la familia- puedan tener descendencia a través de la maternidad subrogada, quedando prohibido este método para aquellas personas que viven solas, además de no prever la posibilidad de que un varón recurra a este tipo de técnica.

Es importante mencionar que al definir en el artículo 146 del Código Civil para la Ciudad de México, al matrimonio como la unión libre de dos personas para realizar la comunidad de vida, en donde ambos se procuran respeto, igualdad y ayuda

39 Gilbert Hoтtors, ¿Qué es la bioética?, México, Fontamara, 2011, p. 45.

40 Código Civil para el estado de Tabasco, nota 38.

41 Ibid., artículo 327 del Código Civil para el estado de Tabasco.

42 Ibid., último párrafo del artículo 92 del Código Civil para el estado de Tabasco.

43 Ibid., artículo 360 del Código Civil para el estado de Tabasco.

44 Código Civilpara elDistritoFederal, enhttp://www.aldf.gob.mx/archivo-2fd95a8c6ed782165d78dc80b1242d2f.pdf, fecha de consulta: 20 de diciembre de 2014. 
mutua, ${ }^{45}$ y considerando que en la capital de la República Mexicana está permitido el matrimonio entre parejas del mismo sexo, es de concluirse que estas últimas también podrian recurrir a la gestación subrogada.

Asimismo, y al igual que en el estado de Tabasco, el artículo 326 del Código Civil para la Ciudad de México establece que no se podrá impugnar la paternidad de los hijos que durante el matrimonio conciba su cónyuge mediante técnicas de fecundación asistida, si hubo consentimiento expreso, en llevar a la práctica tales métodos. ${ }^{46}$ Por disposición del artículo 1803 de este ordenamiento, el consentimiento es expreso cuando se manifiesta verbalmente, por escrito o por signos inequívocos. ${ }^{47}$

\subsection{Sinaloa}

A diferencia del estado de Tabasco y la Ciudad de México, el Código Familiar del estado de Sinaloa, en su artículo 282, define a la reproducción humana asistida como las prácticas clinicas y biológicas para la creación de un nuevo ser humano, logrado mediante el conjunto de técnicas científicamente acreditadas y autorizadas por la Secretaría de Salud, y realizadas con la intervención del personal de la salud, constituidas por métodos de fertilización de células germinales, gametos, de uno o ambos sexos; además de la reproducción de cigotos y embriones que permita la procreación fuera del proceso natural, de la pareja infértil o estéril. ${ }^{48}$

Dentro de las técnicas de reproducción asistida, el artículo 283 del Código Familiar del Estado de Sinaloa reconoce a la maternidad subrogada efectuada a través de la práctica médica mediante la cual, una mujer gesta el producto fecundado por un hombre y una mujer, cuando la mujer padece imposibilidad física o contraindicación médica para llevar a cabo la gestación en su útero y es subrogada por una mujer gestante que lleva en su útero el embrión de los padres subrogados, cuya relación concluye con el nacimiento. ${ }^{49}$

Los requisitos que la legislación sinaloense exige para ser madre subrogada gestante son: ${ }^{50}$

- Tener entre veinticinco y treinta y cinco años de edad.

- Tener, al menos, un hijo consanguíneo sano.

- Contar con una buena salud psicosomática.

- Haber dado su consentimiento voluntario para prestar su vientre.

\footnotetext{
45 Idem.

46 Idem.

47 Idem

48 Código Familiar del estado de Sinaloa, en http://www.laipsinaloa.gob.mx/images/stories/ARCHIVOS\%20PUBLICOS/Leyes\%20Estatales\%20Actuales/codigo\%20civil.pdf, fecha de consulta: 26 de diciembre de 2014.

49 Idem.

50 Ibid., artículos 283, 285, 286, 292 del Código Familiar del Estado de Sinaloa.
} 
- No padecer alcoholismo, drogadicción, tabaquismo o alguna otra toxicomanía.

- Acreditar, mediante dictamen médico, que no estuvo embarazada durante los trescientos sesenta y cinco dias previos a la implantación de la mórula, ${ }^{51}$ y que no ha participado en más de dos ocasiones consecutivas en dicho procedimiento.

- Comprobar que su entorno familiar sea estable, libre de violencia y su condición económica y social sea favorable para su adecuado desarrollo. Lo anterior se certificará a través de una visita domiciliaria practicada por personal de la unidad de trabajo social del hospital tratante.

- Realizarse junto con el padre subrogatorio todos los estudios que establezca la Secretaría de Salud y que sean necesarios para garantizar la salud física y mental de los implicados, a fin de evitar poner en riesgo el bienestar y el sano desarrollo del feto durante el periodo gestacional. El médico tratante será el encargado de practicar los exámenes médicos previos a la implantación. ${ }^{52}$

Por su parte, dentro de las modalidades de la maternidad sustituta que se reconocen en el Estado de Sinaloa, se encuentran las siguientes: ${ }^{53}$

- Subrogación total, que implica que la mujer gestante sea inseminada aportando sus propios óvulos, y que después de la gestación y el parto, entregue el hijo a la pareja o persona contratante.

- Subrogación parcial, que es la que se da cuando la gestadora es contratada exclusivamente para portar en su vientre un embrión fecundado in vitro que le ha sido trasplantado, pero que proviene de la unión de espermatozoide y óvulo de la pareja o persona contratante.

- Subrogación altruista, que opera cuando una mujer acepta gestar por cuenta de otra de manera gratuita.

- Subrogación onerosa, se produce cuando una mujer acepta embarazarse en lugar de otra, tal y como si se tratase de un servicio, por el cual se paga una cantidad cierta y determinada, además de los gastos de la gestación.

La manera de llevar a cabo la maternidad subrogada en Sinaloa es a través de un instrumento que podrá ser suscrito por las partes, siempre que posean capacidad de goce y ejercicio; se trate de ciudadano mexicano; y la madre subrogada demuestre mediante certificado médico, expedido por el médico tratante, la imposibilidad física o contraindicación médica para llevar a cabo la gestación en su útero. ${ }^{54}$ En

51 De acuerdo con Stella Martínez se denomina mórula al segundo estadio de evolución de un preembrión, a partir de que la división de este alcanza las dieciséis células. En la especie humana esta etapa se alcanza a los tres o cuatro días después de la fecundación. Véase Stella Maris MARTínez, Manipulación genética y derecho penal, Buenos Aires, Universidad, 1994, p. 41.

52 Artículo 291 del Código Familiar del estado de Sinaloa, nota 48.

53 Ibid., artículo 284 del Código Familiar del estado de Sinaloa.

54 El médico tratante deberá extender y solicitar los certificados médicos que acrediten que la madre subrogada presenta imposibilidad física o contraindicación médica para llevar a cabo la gestación en su útero. 
el caso de la mujer gestante, se debe acreditar su aceptación para que se lleve a cabo la implantación de la mórula; para procurar el bienestar y sano desarrollo del feto durante el periodo gestacional, y a concluir su relación subrogada, respecto a la persona menor y los padres subrogados, con el nacimiento. ${ }^{55}$

A consecuencia del reconocimiento que Sinaloa hace de la maternidad subrogada como un servicio, en el referido instrumento deberá asentarse el lugar, año, mes, dia y hora en que hubiere sido otorgado para proceder a su firma por parte de la madre y padre subrogados, la madre subrogada gestante, el intérprete, si fuera necesario uno, el notario público, el director de la clínica o centro hospitalario ${ }^{56}$ - no habiendo lugar a la representación legal en el caso de la firma, pues los derechos y las obligaciones que de él emanan son personalísimos- ${ }^{57}$ Posteriormente, el instrumento deberá ser notificado en sus efectos a la Secretaría de Salud y al Oficial del Registro Civil, para que el estado de la persona menor nacida mediante esta práctica, sea contemplado en su filiación como hijo desde el momento de la fecundación de sus progenitores biológicos, es decir, madre y padre o madre subrogados. ${ }^{58}$

Al otorgarle el Código Familiar de Sinaloa una especial importancia a la voluntad que manifiesten las partes para la realización del instrumento de la maternidad subrogada, por consecuencia, la nulidad de este documento tendrá lugar cuando exista error o dolo, respecto a la identidad de los padres subrogados por parte de la mujer gestante; ${ }^{59}$ medie algún vicio de la voluntad relativo a la identidad de las personas; cuando estas últimas incumplan con los requisitos y formalidades que exige el mismo Código Familiar, y en aquellos casos en que se establezcan en el instrumento compromisos o cláusulas que atenten contra el interés superior del niño, la dignidad humana o contravengan el orden social y el interés público. ${ }^{60}$

La nulidad del mencionado instrumento no exime a las partes de las responsabilidades adquiridas y derivadas de su existencia. Reconociéndose, por disposición del artículo 296 del Código Familiar de Sinaloa, el derecho de la mujer gestante para demandar civilmente a la madre y al padre subrogados el pago de gastos médicos, en caso de patologías que deriven de una inadecuada atención y control médico prenatal y posnatal. ${ }^{61}$

En cuanto al certificado de nacimiento - al tratarse del documento expedido por el médico autorizado o tratante que haya asistido a la mujer gestante en el nacimiento del menor de edad- deberá señalar que la maternidad fue derivada de

55 Artículo 290 del Código Familiar del estado de Sinaloa, nota 48.

56 Ibid., artículo 287 del Código Familiar del estado de Sinaloa.

57 Ibid., artículo 286 del Código Familiar del estado de Sinaloa.

58 Ibid., artículo 293 del Código Familiar del estado de Sinaloa.

59 Ibid., artículo 295 del Código Familiar del estado de Sinaloa. Es necesario mencionar que de acuerdo con el artículo 297 del Código Familiar de Sinaloa, se harán acreedores a las responsabilidades civiles y penales aquellos médicos tratantes que realicen la implantación o fecundación de embriones humanos sin el consentimiento y plena aceptación de las partes que intervienen.

60 Ibid., artículo 288 del Código Familiar del estado de Sinaloa.

61 Ibid., artículo 296 del Código Familiar del estado de Sinaloa. 
una técnica de apoyo a la reproducción humana o práctica médica, denominada maternidad subrogada. ${ }^{62}$

Finalmente, cabe mencionar que en el estado de Sinaloa se prohíbe a las personas casadas donar esperma u óvulo artificialmente a madre portadora y a reclamar la progenitura, a no ser que obtuvieren el consentimiento de su cónyuge. A lo anterior se adiciona que aún en el caso de que demandaren la paternidad o maternidad, no podrán recibir la custodia del producto de la inseminación, salvo que exista incapacidad o muerte de la madre y esta última tenga la anuencia de su cónyuge. ${ }^{63}$

\subsection{Coahuila}

Digna de resaltarse es la expresión "asistencia médica para la procreación”, a la que por disposición del artículo 482 del Código Civil de Coahuila se define como las prácticas clínicas y biológicas que permiten la concepción in vitro, la transferencia de embriones y la inseminación artificial, así como toda técnica de efecto equivalente que permita la procreación fuera del proceso natural. ${ }^{64}$

De acuerdo con el mismo ordenamiento, previo al inicio del tratamiento de asistencia médica, los cónyuges deberán dar su consentimiento en escritura pública otorgada ante notario y justificar con certificación de tres médicos especialistas en la materia, de los cuales uno lo será de la Secretaría de Salud del Estado, la necesidad de someterse a dicho tratamiento. De lo anterior se sigue, que ante el consentimiento dado para someterse a este tipo de procedimiento, solo se podrá impugnar la filiación, cuando el nacimiento del hijo no derivó del tratamiento empleado o que el consentimiento fue privado de efecto ${ }^{65}$ La revocación de pleno derecho del consentimiento opera con la muerte de quien lo otorgó, si antes no se hubiere producido la fecundación. ${ }^{66}$

Conforme al artículo 483 del Código Civil para el estado de Coahuila de Zaragoza, las técnicas de reproducción humana asistida solo podrán ser utilizadas por matrimonios ${ }^{67}$ o por aquellos que vivan en concubinato, quienes deberán acreditar que después de cinco años, por razones biológicas, no han podido engendrar o concebir, sin que sean estériles o infértiles. En caso de esterilidad o infertilidad, médicamente diagnosticada, se permite a los cónyuges o concubinos la inseminación o fecundación heteróloga. ${ }^{68}$

62 Ibid., artículo 294 del Código Familiar del estado de Sinaloa.

63 Ibid., artículo 286 del Código Familiar del estado de Sinaloa.

64 Código Civil para el estado de Coahuila de Zaragoza, en http://coahuila.gob.mx/archivos/pdf/ C\%C3\%B3digo\%20Civil\%20para\%20el\%20Estado\%20de\%20Coahuila.pdf, fecha de consulta: 21 de diciembre de 2014.

65 Ibid., artículo 486 del Código Civil para el estado de Coahuila de Zaragoza.

66 Ibid., artículo 487 del Código Civil para el estado de Coahuila de Zaragoza

67 Ibid. El artículo 488 del Código Civil para el estado de Coahuila de Zaragoza dispone que si el matrimonio se disuelve por muerte, divorcio o nulidad, la mujer no podrá ser inseminada con material 368 genético de quien fuera su marido. Empero, si hubiere un óvulo fecundado en forma extracorpórea, deberá ser implantado a la viuda, divorciada o a la mujer cuyo matrimonio se anuló. 
Por su parte, la Secretaría de Salud del Estado de Coahuila deberá entregarles, a los destinatarios de las técnicas de reproducción humana asistida, una guía que contenga las disposiciones legales sobre procreación asistida y la descripción de las técnicas, ${ }^{69}$ así como informarles de las posibilidades que la ley ofrece en materia de adopción. ${ }^{70}$

Un aspecto por considerar es la antinomia que existe entre el artículo 491 del Código Civil de Coahuila que decreta la inexistencia del contrato de maternidad subrogada y el artículo 482 del mismo ordenamiento que al permitir emplear "toda técnica que favorezca la procreación fuera del proceso natural”, hace procedente recurrir al alquiler de vientre.

\subsection{Otros estados}

Otro de los ordenamientos que se destaca por reconocer el derecho de los cónyuges para utilizar los métodos de fecundación artificial o asistida, y de esterilización, temporal o permanente, ${ }^{71}$ es el Código Familiar para el estado de San Luis Potosí, que distingue a la reproducción humana asistida de las técnicas de reproducción asistida.

En primer término, por disposición del artículo 236 del ordenamiento en comento, se entiende por reproducción humana asistida la que se verifica a través de la participación de terceras personas y el empleo de técnicas biológicas de reproducción sin coito de la pareja. ${ }^{72}$ Mientras que las técnicas de reproducción asistida son aquellas donde la unión de las células germinales o la implantación del embrión en el útero se logra mediante la intervención directa en el laboratorio. ${ }^{73}$

Las técnicas de reproducción asistida, que por disposición del artículo 238 del Código Familiar del estado de San Luis Potosí pueden practicarse son: ${ }^{74}$

- Transferencia intratubaria de cigoto o transferencia tubárica de embriones, consistente en la colocación de los embriones en la matriz de la mujer, utilizando material quirúrgico.

- Fertilización in vitro, método en el que los espermatozoides previamente preparados y seleccionados son depositados en una caja de vidrio que contiene un medio de cultivo especial.

69 Ibid., artículo 484 del Código Civil para el estado de Coahuila de Zaragoza.

70 Ibid., artículo 485 del Código Civil para el estado de Coahuila de Zaragoza.

71 Artículo 28 del Código Familiar para el estado de San Luis Potosí, en http://docs.mexico.justla. com.s3.amazonaws.com/estatales/san-luis-potosi/codigo-familiar-para-el-estado-de-san-luispotosi.pdf, fecha de consulta: 19 de diciembre de 2014.

72 Ibid., artículo 236 del Código Familiar del estado de San Luis Potosí.

73 Ibid., artículo 238 del Código Civil Familiar para el estado de San Luis Potosí.

74 Idem. 
- Fertilización ICSI, ${ }^{75}$ utilizada cuando los espermatozoides son muy pocos, o su capacidad de fertilización está disminuida.

De lo anterior, en correlación con el artículo 243 del Código Familiar de San Luis Potosí, que decreta la inexistencia de la maternidad sustituta, se colige que no es posible recurrir a este tipo de técnica de reproducción asistida en este Estado, ya que al no producir efecto legal alguno, si un embrión fuese implantado en una mujer distinta a la cónyuge o concubina, la maternidad se le atribuirá a la prime$\mathrm{ra}^{76}$ de conformidad con el principio de mater sempre certa est.

Por lo que respecta al Código de Familia para el estado de Sonora reconoce en su artículo 203 que el parentesco puede ser consanguíneo, por afinidad y voluntario. ${ }^{77}$ Por disposición del artículo 213 del mismo ordenamiento, la filiación consanguínea es el vínculo de parentesco que surge de la relación genética entre dos personas, por el solo hecho de la procreación, incluyendo la reproducción asistida con material genético de ambos padres. ${ }^{78}$ Mientras que el parentesco voluntario es el que nace de la adopción, del nacimiento obtenido mediante las técnicas de reproducción asistida autorizadas por los cónyuges y de la afiliación o acogimiento de menores, siempre que este se prolongue por más de un año con todas las características y fines de la relación paterno-filial. ${ }^{79}$

Asimismo, al regularse los efectos filiatorios de la voluntad procreacional, el artículo 207 del Código de Familia de Sonora dispone que cuando el embarazo se obtenga por medio de técnicas de reproducción asistida y se use material genético de personas distintas de uno o ambos cónyuges o concubinos, estos últimos serán considerados como padres biológicos del hijo que nazca de esa concepción, siempre que hubieran otorgado su consentimiento ${ }^{80}$ para la utilización de estos métodos. ${ }^{81} \mathrm{Al}$ equipararse, en este caso, el consentimiento de los cónyuges con la cohabitación para efectos de la paternidad, por consecuencia se excluye cualquier derecho u obligación del donante. ${ }^{82}$

75 La fertilización ICSI, a que hace referencia el Código de San Luis Potosí, se refiere a la inyección intracitoplasmática, la cual consiste en la inyección de un solo espermatozoide en el interior del óvulo descongelado, tras haberse conservado en frío. Véase José Manuela Martínez-Pereda Rodríguez y J. M. Massigoge Benegio, La maternidad portadora subrogada o de encargo en el derecho español, Madrid, Dykinson, 1994, p. 90.

76 Artículo 243 del Código Civil Familiar para el estado de San Luis Potosí, nota 71.

77 Código de Familia para el estado de Sonora, Poder Legislativo del estado de Sonora, en http:// transparencia.esonora.gob.mx/NR/rdonlyres/954A41CE-2B36-447B-94F6-BE8DD4444253/64 550/CODIGODEFAMILIAPARAELESTADODESONORA.pdf, fecha de consulta: 23 de diciembre de 2014.

78 Ibid., artículo 213 del Código de Familia para el estado de Sonora.

79 Ibid., artículo 206 del Código de Familia para el estado de Sonora.

80 Por disposición de la fracción XV del artículo 156 del Código de Familia de Sonora son causas de divorcio por culpa, el someterse uno de los cónyuges a métodos de reproducción asistida con material genético de terceros, sin consentimiento del otro. En el divorcio culpable, el punto segundo del artículo 179 del mismo ordenamiento legal establece que el hijo nacido por reproducción asistida quedará al lado de su madre como única titular de la patria potestad.

81 Artículo 207 del Código de Familia para el estado de Sonora, nota 77.

82 Ibid., artículo 208 del Código de Familia para el estado de Sonora. 
La autorización de los cónyuges para recurrir a la reproducción asistida, admitiendo la paternidad o maternidad del producto, deberá hacerse ante el director de la clínica o centro hospitalario, ante notario público o por acuerdo privado suscrito ante testigos, ${ }^{83}$ para dejar constancia de esta nueva fuente de la paternidad o la maternidad.

Al igual que el estado de Querétaro, el artículo 207 del Código de Familia de Sonora reconoce el derecho del hijo para solicitar - al llegar a su mayoría de edadinformes sobre el padre biológico en los mismos casos que en la adopción plena, sin que proceda el reclamo de ningún derecho filiatorio. ${ }^{84}$

Es de destacarse que la fracción XVIII del artículo 199 del Código Civil de Morelos, ${ }^{85}$ la fracción XVII del artículo 175 del Código Familiar del mismo estado ${ }^{86}$ y la fracción XX del artículo 267 del Código Civil para el estado de Colima ${ }^{87}$ coinciden en establecer como causas de divorcio la inseminación artificial o las técnicas de reproducción asistida en la mujer, sin el consentimiento de alguno de los cónyuges, pero el último de los ordenamientos, en su artículo 410-B permite la adopción plena del producto de un embarazo logrado como consecuencia del empleo de inseminación artificial o fertilización in vitro con la participación de una madre sustituta que haya convenido con los presuntos padres darlo en adopción. ${ }^{88}$

En el caso de Baja California Sur, el divorcio necesario únicamente procede cuando se realiza la inseminación artificial heteróloga de la mujer o la implantación en ella de un óvulo fecundado por personas ajenas al matrimonio, sin el consentimiento del marido. ${ }^{89} \mathrm{El}$ plazo de caducidad para demandar el divorcio comenzará a contar desde que el cónyuge conozca el método usado por su cónyuge para alcanzar su embarazo. ${ }^{90}$

En el Código Civil del estado de México, ${ }^{91}$ y en los Códigos Familiares de los estados de Zacatecas $^{92}$ y Michoacán ${ }^{93}$ se reconoce el derecho de los cónyuges a decidir de manera

83 Idem.

84 Ibid., artículo 207 del Código de Familia para el estado de Sonora.

85 Código Civil para el estado Libre y Soberano de Morelos, en http://instituto.congresomorelos.gob. $\mathrm{mx} /$ nuestras_leyes/pdf/codigos/Codigo_CIVILEM.pdf, fecha de consulta: 17 de diciembre de 2014.

86 Código Familiar para el estado Libre y Soberano de Morelos, en http://instituto.congresomorelos.gob. mx/nuestras_leyes/pdf/codigos/Codigo_CIVILEM.pdf, fecha de consulta: 17 de diciembre de 2014 .

87 Nuevo Código Civil para el estado de Colima, en http://www.congresocol.gob.mx/leyes/codigo_civil. pdf, fecha de consulta: 25 de diciembre de 2014.

88 Idem.

89 Fracción III del artículo 289 del Código Civil para el estado Libre y Soberano de Baja California Sur, en http://www.cbcs.gob.mx/index.php?option=com_content\&id=2097\&Itemid=154PARA, fecha de consulta: 13 de diciembre de 2014.

90 Ibid., artículo 298 del Código Civil del estado Libre y Soberano de Baja California Sur.

91 Artículo 4.16 del Código Civil del estado de México, en http://www.infosap.gob.mx/leyes_y_codigos.html, fecha de consulta: 19 de diciembre de 2014.

92 Artículo 123 del Código de Familia del estado de Zacatecas, en http://docs.mexico.justia.com. s3.amazonaws.com/estatales/zacatecas/codigo-familiar-del-estado-de-zacatecas.pdf, fecha de consulta: 21 de diciembre de 2014.

93 Artículo 150 del Código Familiar para el estado de Michoacán de Ocampo, en http://micrositios.dif.gob. $\mathrm{mx} / \mathrm{pdmf} /$ files / 2014/10/C\%C3\%93DIGO-FAMILIAR-PARA-EL-ESTADO-DE-MICHOAC\%C3\%81N-DE-OCAMPO.pdf, fecha de consulta: 20 de diciembre de 2014. 
libre, responsable e informada sobre el número y espaciamiento de sus hijos, así como a utilizar cualquier método de procreación asistida para lograr su propia descendencia. Al emplear dichos ordenamientos la expresión "cualquier método de reproducción asistida” se considera legal la práctica de la gestación sustituta.

De igual forma, en los referidos ordenamientos, el consentimiento tiene una importancia especial en el caso de la reproducción asistida, al grado que en Zacatecas no está permitido desconocer la paternidad de los hijos que durante el matrimonio conciba su cónyuge mediante técnicas de reproducción asistida, si hubo consentimiento expreso en la práctica de tales métodos. ${ }^{94}$

En el Estado de México, la reproducción asistida a través de métodos de inseminación artificial solo podrá efectuarse con el consentimiento de la mujer a quien haya de practicarse dicho procedimiento. La mujer casada, para ser inseminada, requiere del consentimiento de su cónyuge.$^{95}$ En tanto que la fracción XX del artículo 261 del Código Familiar de Michoacán establece que la falta de consentimiento de uno de los cónyuges es causa de divorcio. ${ }^{96} \mathrm{Y}$, finalmente, en Zacatecas y Michoacán entre el hijo producto de la reproducción asistida y los cónyuges o concubinos que hubieren procurado y consentido el nacimiento existirá parentesco por consanguinidad. ${ }^{97}$

\section{PROBLEMÁtica JURÍdicA}

El estado de Tabasco - al igual que la India, Ucrania, Reino Unido, Grecia y algunas ciudades de Estados Unidos- ha recurrido a la figura del contrato como el medio para acceder a la maternidad subrogada en sus diferentes modalidades, pero infortunadamente su legislación es omisa en lo referente a los requisitos que deben cumplir los contratantes además de no especificar la naturaleza jurídica, los elementos y las características del acto jurídico que ha de celebrarse en las distintas modalidades de maternidad sustituta que se encuentran tipificadas en esta entidad federativa.

Con excepción de la regulación de los requisitos que debe reunir la madre subrogada gestante, el instrumento para la maternidad subrogada previsto en el Código Familiar del estado de Sinaloa presenta las mismas omisiones que el contrato contemplado en el Código Civil de Tabasco. Mientras que en las legislaciones de la Ciudad de México, estado de México, Colima, Sonora, Zacatecas y Michoacán, a pesar de permitir el acceso a la subrogacía, se omite regular el acto jurídico para llevarla a cabo. 
En este contexto, la doctrina jurídica en sus diversos intentos de encuadramiento dentro de las figuras negociables tradicionales ha llegado a considerar al contrato de subrogación como de arrendamiento de obra debido a que la obligación consiste en crear un bebé, ${ }^{98}$ refutando su equiparación con el contrato de arrendamiento de cosa, porque el cuerpo humano o parte de él no es jurídicamente "cosa". Otra postura teórica es la que considera que la maternidad subrogada se trata en realidad de la prestación de una conducta de contenido complejo, que comprende deberes de diligencia, vigilancia médica, régimen alimenticio, vida ordenada, comunicación de incidencias, etc. ${ }^{99}$

Incluso, de acuerdo con las modalidades de la maternidad subrogada, se ha considerado que el contrato será de servicio cuando se trate del arrendamiento de útero. ${ }^{100}$ En tanto que cuando la portadora aporte óvulos y vientre - genética y gestación - pudiera aparecer como un contrato mixto de prestación de servicios y de cosa. Atendiendo a esta última distinción, en Estados Unidos en el primer caso, es decir, cuando se aporta exclusivamente el vientre para recibir uno o varios cigotos producidos con material genético ajeno se celebran contratos de subrogación gestacional comúnmente denominados contratos incubadora. Mientras que se concerta un contrato de subrogación tradicional cuando la madre gestante aporta el material genético y su cuerpo. ${ }^{101}$ Distinción esta última que en los casos de Tabasco y Sinaloa es inexistente.

Otro enfoque es aquel que considera que el contrato de maternidad subrogada no es susceptible de clasificación entre los tipos de contratos conocidos. Dentro de este enfoque, el connotado doctor Gutiérrez y González señala que el acto jurídico que se efectúa para llevar a cabo la maternidad subrogada es un contrato de gestación alienus un vitro, al que define como el acuerdo de voluntades que puede celebrarse, en forma gratuita u onerosa, entre una pareja en matrimonio o en concubinato, o una mujer o un hombre soltero, denominados tradens, y otra mujer, a la que se le llama accipiens, quien se obliga a recibir en su genital adecuado, el producto de una inseminación alienus in vitro, por todo el tiempo que dure la gestación, y hasta que nazca el producto de la concepción, con el deber de entregar ese fruto, de inmediato o cuando se lo pida, dentro de los seis siguientes meses de nacido el producto. ${ }^{102}$

De igual manera, Martínez-Pereda y Massigoge Benegio consideran que el contrato de maternidad subrogada es un contrato que no puede encasillarse ni equipararse con otras tradicionales figuras contractuales, porque se trataria de una figura

98 María CARCABA Fernández, Los problemas jurídicos planteados por las nuevas técnicas de procreación, op. cit., nota 10, p. 168.

99 Luis H. Clavería Gosálbez, "Las categorías negociales y su adaptación en función de la reproducción humana”, en II Congreso Mundial Vasco, "La filiación a finales del siglo XX", pp. 239-240.

100 Miguel Ángel Soto LAMAdrid, Biogenética, filiación y delito. La fecundación artificial y la experimentación genética ante el derecho, op. cit., nota 18, p. 328.

101 Hernán CoRral TAlciani, "Maternidad Subrogada: Sobre la pretensión de formalizar la filiación perseguida mediante la adopción o la recepción de su práctica en el extranjero”, op. cit., nota 14, p. 172.

102 Ernesto Gutiérrez y GonzÁlez, Derecho civil para la familia, México, Porrúa, 2004, p. 589. 
innominada de carácter mixto, en cuanto participa de la locatio operis, de la locatio operarum, del mandato; requiere la colaboración de terceros, centro sanitario y médicos; puede ser onerosa o gratuita; está sujeta en cuanto a su consecuencia a una condición mixta. En fin, la complejidad es muy grande y no permite su encuadre en las habituales figuras contractuales, ${ }^{103}$ encontrándonos frente a actos jurídicos hoy atípicos, pero tipificables en el futuro y pertenecientes al derecho de familia. ${ }^{104}$

Bajo esta óptica que atribuye un carácter especial al contrato de maternidad subrogada, sus principales características son:

- Es un acuerdo por virtud del cual una pareja en matrimonio o en concubinato, una mujer o un hombre soltero así como una pareja homosexual contrata con una mujer fértil, para que esta última dé a la luz a una criatura.

- Puede ser a título gratuito u oneroso.

- Obligación de la madre subrogada de inseminarse con el semen del marido de la mujer contratante o de aceptar la implantación de un embrión formado por fecundación in vitro, con gametos de la pareja o de un miembro de la pareja y donante o de terceros. ${ }^{105}$

- Renuncia de la gestante a todos los derechos filiales respecto al niño que ha parido. ${ }^{106}$

- La entrega del menor a la pareja contratante.

Empero, además del tipo de contrato y de su carácter oneroso o gratuito, otros problemas presentes son, en primer término, el relativo a la eficacia de los actos jurídicos que han de celebrarse en las distintas modalidades de maternidad sustituta que se encuentran tipificadas y, en segundo término, los efectos que dichos actos generan. De acuerdo con la teoría clásica francesa, todo acto jurídico debe cumplir o reunir ciertas condiciones para formarse, que son presupuestos de su existencia y de su eficacia. ${ }^{107}$

Primeramente, para que un contrato exista debe contar con el consentimiento de las partes y recaer sobre un objeto posible. Una vez constituido con todos sus elementos de existencia, para ser perfecto y producir efectos jurídicos plenos el contrato debe reunir los requisitos de validez, consistentes en la capacidad legal de las partes o de una de ellas; que el objeto, o su motivo o fin sea lícito; que el consentimiento se manifieste en la forma que la ley establece y exento de vicios del

103 José Manuel Martínez-Pereda Rodríguez y J. M. Massigoge Benegiu, La maternidad portadora subrogada o de encargo en el derecho español, op. cit., nota 75, pp. 135-136.

104 Luis H. Clavería GosálBez, "Las categorías negociales y su adaptación en función de la reproducción humana”, op. cit., nota 99, pp. 239-240.

$374 \quad 105$ Maricruz Gómez de LA ToRre VARGAs, La fecundación in vitro y la filiación, Santiago, Editorial Jurídica de Chile, 1993, p. 205.

106 Ibid., p. 206.

107 Manuel Bejarano Sánchez, Obligaciones civiles, México, Oxford University Press, 1999, p. 41. 
consentimiento, ya que si la decisión proviene de una creencia equivocada (error), ha sido obtenida o mantenida por engaños (dolo) o ha sido arrancada con amenazas (violencia o temor), entonces es una voluntad viciada que anula el contrato. ${ }^{108}$

Lo anterior, en el caso del denominado contrato de gestación subrogada, conlleva otro problema, determinar si el contrato es inexistente ante la falta de los elementos de existencia o se trata de un acto nulo ante la ausencia de requisitos de validez.

La mayoria de los autores se inclina por considerar que este tipo de acto jurídico adolece de una nulidad absoluta que impide que surta efecto alguno y, por tanto, esté desprovisto de acción para hacer efectivo su cumplimiento, debido a que la disposición de embriones o de un ser humano son considerados objetos ilícitos porque vulneran las normas de orden público o a las buenas costumbres (de observancia obligatoria para los particulares por prescripción legal). Se equipara a un contrato de prostitución que descuartiza la maternidad ${ }^{109} \mathrm{y}$ altera el estado civil de las personas. ${ }^{110}$ Muchas veces supone un fraude a las normas de la filiación natural y a las de adopción; cae dentro del imperio del derecho penal, pues se acerca a la compraventa de niños además de incitar al abandono de los mismos, y en ocasiones lleva consigo un delito de suposición de parto. ${ }^{111}$

Desde la posición contraria, en cambio, se sostiene que jurídicamente al no poder ser objeto de contrato, los embriones, los gametos o el cuerpo humano (res extra commercium), falta uno de los elementos esenciales del acto jurídico, lo que provoca la inexistencia del contrato de maternidad subrogada. ${ }^{12}$

Ante los cuestionamientos doctrinales a la figura del contrato de subrogacía, que a su vez carece de reconocimiento como fuente de la filiación en atención a la posible invocación del principio fraus omnia corrumpit, se ha generado que en Sinaloa se recurra a la inscripción en el Registro Civil del instrumento de subrogacía, como medio para establecer la relación filial entre los contratantes y el menor.

Por su parte, en el estado de Tabasco, tratándose de los hijos nacidos como resultado de la participación de una madre gestante sustituta, da lugar a la presunción de la maternidad en favor de la madre contratante. En tanto que en el caso de la maternidad subrogada, se recurre a la figura jurídica de la adopción del menor, ${ }^{113}$ cuya aceptación también tiene lugar en Colima.

\footnotetext{
108 Ibid., p. 73.

109 Mirta Videla, Los derechos humanos en la bioética, Buenos Aires, 1999, p. 159.

110 Silvana María Chiapero, Maternidad subrogada..., op. cit., nota 12, p. 120.

111 María Carcaba Fernández, Los problemas jurídicos planteados por las nuevas técnicas de procreación, op. cit., nota 10, p. 169.

112 La inexistencia del contrato de maternidad ha sido sostenida en el Código Civil para el Estado de Coahuila y en el Código Familiar para el Estado de San Luis Potosí. Véase C. Carmen García Mendieta, "Fertilización extracorpórea: aspectos legales", en Ciencia y Desarrollo 65 (noviembre y diciembre 1985), p. 39.

113 Artículo 92 del Código Civil para el estado de Tabasco, nota 38.
} 
A pesar de que es probable que el origen de la adopción se encuentre en la Antigüedad -en la que esta institución era considerada un negocio jurídico de derecho de familia, en la que los padres biológicos entregaban a los padres adoptivos al menor adoptado, ${ }^{114}$ quien llegaba a ser completamente ajeno a su antigua familia-, consideramos ilegal su práctica para justificar la entrega de un ser humano concebido a través de la subrogacía, debido a las diferencias que existen entre ambas instituciones.

La adopción es una institución jurídica, por medio de la cual una o dos personas establecen un lazo de filiación con un menor que no es su hijo. ${ }^{115}$ A la adopción la guian los principios de gratuidad, no negociabilidad, protección del interés superior, remediabilidad, subsidiariedad, judiciabilidad y protección del derecho a la identidad del adoptado, los cuales son inexistentes en el caso de la maternidad subrogada, debido a que no hay un niño previamente en situación de vulnerabilidad (abandono, orfandad o maltrato), sino que se diseñan los planes para "crear" al menor, al cual debe renunciar la mujer que lo gestó, en la mayoría de los casos a cambio de una cantidad de dinero.

Es así que el tratamiento legislativo que existe en el caso de maternidad subrogada, ubicándola como una técnica autorizada —en los estados de Tabasco, Sinaloa, estado de México, Zacatecas, Michoacán y Ciudad de México- hasta su prohibición o no reconocimiento, como ocurre en los estados de Querétaro y San Luis Potosí, permea en los efectos que provoca, los cuales no son reconocidos en cualquier caso. A menudo suelen presentarse dificultades en relación con el establecimiento o el reconocimiento de la paternidad legal de los niños nacidos a través del alquiler de vientre con graves repercusiones en lo referente a su identidad, nacionalidad y estatus migratorio así como en la atribución de los deberes parentales y derechos sucesorios.

A este respecto se hace necesaria la referencia al caso 25358/12, presentado por los esposos Paradiso y Campanelli contra el Gobierno italiano, ${ }^{116}$ así como en los interpuestos en contra de Francia por Mennesson (demanda 65192/11) y Labassee (demanda 65941/11), ${ }^{117}$ en los que el Tribunal Europeo de Derechos

114 Hernán CoRral TAlciani, "Maternidad Subrogada: Sobre la pretensión de formalizar la filiación perseguida mediante la adopción o la recepción de su práctica en el extranjero”, op. cit., nota 14, p. 178.

115 Ingrid Brena Sesma, "La gestación subrogada: ¿una nueva figura del derecho de familia?”, en Ingrid Brena Sesma (coord.), Reproducción asistida, México, UNAM, 2012, p, 153.

116 Los esposos Paradiso y Campanelli demandan, en su nombre y en el del niño nacido en Rusia en virtud de un contrato de subrogacía, al Estado italiano por negarse a inscribir en el Registro Civil el certificado emitido por las autoridades rusas que los reconoce como padres del menor. Véase http://hudoc.echr.coe.int/eng\#\{“languageisocode”:[“FRE”],"itemid”:[“001-150770”]\}, fecha de consulta: 24 de diciembre de 2015

117 Las autoridades judiciales francesas se negaron a inscribir en el Registro Civil las actas de nacimiento de los menores por considerar que tal medida era contraria al orden público francés, que establece la indisponibilidad del cuerpo humano y del estado de las personas (arts. 16-7 y 16-9 del Código Civil francés). Asimismo, la denegación a inscribir un acta de notoriedad de la relación de filiación así como la falta de reconocimiento de la filiación a través de la adopción o la filiación paterna biológica que existía en este asunto, son sustentadas en la nulidad del contrato de gestación por subrogación, siendo inadmisible ante un fraude a la ley (fraus omnia corrumpit) invocar el inte- 
Humanos ha determinado que la denegación de la inscripción de la filiación de los menores nacidos en virtud de un contrato de gestación por sustitución en un país extranjero transgrede el derecho a la vida privada y familiar de los niños, consagrado en el artículo 8 del Convenio Europeo para la Protección de los Derechos Humanos y de las Libertades Fundamentales, bajo la consideración de que la noción de familia no se reduce a las relaciones fundadas en el matrimonio, sino puede atender a la calidad de estas, e incluso englobar el papel asumido por el adulto hacia el niño u otros vínculos familiares de facto, como cuando las partes cohabiten fuera de cualquier vínculo marital o la inexistencia de vínculo biológico o cohabitación. ${ }^{118}$

En este contexto, y frente a la determinación de algunos Estados de negar los efectos de la gestación por sustitución, poniendo de relieve la excepción del orden público, consideramos que la interpretación que realiza el Tribunal de Estrasburgo en los referidos casos, prepondera la protección de uno de los principales fines de la ley: el interés superior del menor y el respeto a sus derechos de identidad, vida privada y familiar e intereses patrimoniales. ${ }^{119}$ Evitando que los niños nacidos al amparo de acuerdos de maternidad subrogada se vean privados de padres, estatus legal, bienestar físico y psicológico, además de la debida protección en todos los ámbitos de su vida.

Por supuesto que la práctica del denominado alquiler de vientre, como una realidad que se encuentra presente a nivel mundial y que el derecho está regulando a través de normas individualizadas, como las dictadas por el Tribunal de Estrasburgo que han servido de parámetro a otros órganos jurisdiccionales ${ }^{120}$ para

rés superior del niño garantizado por el artículo 3.1 de la Convención sobre los Derechos del Niño, así como el respeto a la vida privada y familiar previsto en el artículo 8.1 del Convenio Europeo de Derechos Humanos. Véanse ambas demandas en http://hudoc.echr.coe.int/sites/ eng/pages/ search.aspx?i=001-145180*\#\%7B\%22itemid\%22:\%5B\%22001-145180*\%22\%5D\%7D, fecha de consulta: 26 de diciembre de 2015.

118 La noción de familia ha sido establecida en los casos Johnston c. Irlanda, de 18 diciembre 1986; Berrehab c. Holanda, de 21 junio 1988; Keegan c. Irlanda, de 26 de mayo de 1994, recurso 16969/90; Kroon c. Holanda, de 27 de octubre de 1994, recurso 18535/91; Y., Z. c. Reino Unido, de 27 de octubre de 1997, recurso 21830/93; Wagner c. Luxemburgo, de 28 de junio de 2007, recurso 76240/01 y Moretti y Benedetti c. Italia, 27 abril 2010, recurso 16318/07. Véase http:// hudoc.echr.coe.int/eng\#[“languageisocode”:[“FRE”],"itemid”:[“001-150770”]\}, fecha de consulta: 24 de diciembre de 2015

119 En los casos Marckx c. Bélgica y Pla y Puncernau contra Andorra, el Tribunal de Estrasburgo ha admitido que la vida familiar no comprende únicamente las relaciones de carácter social, moral o cultural, engloba también intereses patrimoniales, como lo muestran, particularmente, las obligaciones alimenticias y el lugar atribuido a la reserva hereditaria.

120 La sentencia del Tribunal Supremo alemán (Bundesgerichtshof), pronunciada el 10 de diciembre de 2014, haciendo una interpretación restrictiva del orden público con especial atención en el interés superior del menor, dispone que el reconocimiento en Alemania de una resolución judicial de California relativa al establecimiento de filiación por maternidad subrogada no resulta contraria al orden público en el caso concreto, es decir, toda vez que se trata de madre gestante soltera y uno de los comitentes padre biológico, formando pareja registrada con otro varón. Pero de manera expresa el tribunal se reserva la posibilidad de alcanzar un resultado distinto en situaciones diferentes, en particular en las que ninguno de los comitentes fuera el padre biológico del niño o en el que la madre gestante fuera la madre genética. Véase http://juris.bundesgerichtshof.de/ cgi-bin/rechtsprechung/document.py? Gericht=bgh\&Art=pm\&Datum=2014\&Sort=3\&anz=193\& pos=1\&nr=69759\&linked=bes\&Blank=1\&file=dokument.pdf, fecha de consulta: 26 de diciembre 
resolver los efectos que produce la práctica de la subrogacía, tendrán como herramientas útiles al principio de proporcionalidad, la adecuada ponderación de los principios jurídicos que colisionan en el caso de la gestación por sustitución en convergencia con la aplicación de criterios de razonabilidad, la garantía del contenido esencial de los derechos fundamentales así como los distintos métodos de solución de antinomias.

Pues, a pesar de que se estima adecuado el mecanismo de filiación biológica para la fijación de las relaciones paterno-filiales en los casos de subrogación parcial o gestacional, mientras que la declaratoria de reconocimiento lo es tratándose de la subrogación plena, resulta ineludible romper el dañino silencio legislativo ${ }^{121}$ que infortunadamente impera en los aspectos relacionados con los límites en la aplicación de las técnicas sobre los embriones; el diagnóstico preimplantatorio; la sanidad, la negativa de la mujer a continuar el embarazo o a someterse a todos los cuidados que exige su nueva condición física; cuando el menor nace con malformaciones o anomalias; la muerte de la gestante a consecuencia del parto; la existencia de nacimientos múltiples; la ampliación de las prestaciones en dinero y en especie que establece el seguro social en favor de la madre potencial cotizante que tiene un hijo mediante el alquiler de vientre; el derecho de esta última a disfrutar de un permiso por maternidad o la creación de un permiso especial en el casos de los métodos de reproducción asistida, así como la revocación de consentimiento, que en el caso de divorcio, puede alterar la identidad del menor y la relación filial además de generar las siguientes interrogantes:

¿Es posible abortar? ¿A quién corresponde el derecho de decidir sobre el destino de los embriones? ¿Podrá la madre gestante reclamar su maternidad? ¿Es a la madre subrogada a quien le corresponde la patria potestad del menor? ¿Cómo se determinan los derechos parentales de los padres comitentes? A lo anterior se adiciona el establecimiento de los derechos, las obligaciones y las responsabilidades que les son aplicables a todos los sujetos que pueden intervenir para lograr la fecundación, así como la emisión de los lineamientos que debe reunir la información suministrada por los médicos, siendo necesario contar con el consentimiento informado no solo de la receptora de tales métodos, sino de sus familiares

de 2015. Por su parte, la sentencia dictada el 2 de febrero de 2015 en el recurso 245/2012 por el Tribunal Supremo español — con especial referencia en las disimilitudes que existen con los casos Mennesson y Labassee- confirma la denegación de la inscripción de la filiación de unos menores nacidos de un vientre de alquiler en California, conforme a lo preceptuado en el artículo 10.1 de la Ley 14/2006 de Técnicas de Reproducción Asistida en la que se determina que tales contratos, al ser nulos de pleno derecho, son incompatibles con el orden público. Sin embargo, en atención al interés superior del menor y la atenuación del orden público, dispone que debe permitirse la integración de los menores en su familia, y ante la falta de datos en el procedimiento sobre su situación familiar, insta al Ministerio Fiscal para que inicie las acciones pertinentes para determinar la correcta filiación de los menores y su protección dentro de su propio núcleo familiar a través de figuras como el acogimiento familiar o la adopción, lo cual revela el cumplimiento del artículo 8 del Convenio Europeo. Véase recurso 245/2012 en http://www.poderjudicial.es/search/doAction?action=contentpdf\&data basematch=TS\&reference $=7288332 \&$ links=derecho\%20internacional $\% 20$ privado\&optimize $=201502$ 13\&publicinterface=true, fecha de consulta: 25 de diciembre de 2015.

121 Desde 2010, la Conferencia de La Haya de Derecho Internacional Privado está preparando un convenio específico para regular los acuerdos internacionales de gestación por sustitución. 
y personas más próximas, aspectos todos ellos que ameritan la debida regulación para evitar (o al menor reducir) que las parejas recurran al largo camino judicial.

\section{CONCLUSIÓN}

México cuenta con un marco legislativo parco y disímil en cuanto a la maternidad subrogada, ya que mientras se puede acceder a ella en Tabasco y Sinaloa a través de un contrato o instrumento suscrito por las partes, respectivamente; en Sonora, estado de México, Zacatecas, Michoacán, Colima y la Ciudad de México se autoriza - con el consentimiento de la pareja - su práctica, pero se omite regular el acto jurídico para llevarla a cabo, a diferencia de las legislaciones de Querétaro y San Luis Potosí que prohíben este método de reproducción asistida.

Como consecuencia de lo anterior, la determinación de la relación filial se realiza mediante la inscripción en el Registro Civil del instrumento de subrogacía en el caso de Sinaloa; a través del parentesco voluntario en Sonora, en tanto que a la adopción se recurre en Colima y Tabasco, operando en este último estado, además, la presunción de maternidad en los casos de gestación sustituta. En el resto de los estados que conforman la República Mexicana existe un vacío legal respecto de este medular punto que afecta la identidad, el estatus legal y la vida privada y familiar de los menores, pues si bien se considera adecuado adoptar el mecanismo de filiación biológica para la fijación de las relaciones paterno-filiales en los casos de subrogación gestacional; en tanto que la declaratoria de reconocimiento lo es tratándose de la subrogación plena, debido a la ineficacia de la figura del contrato en el ámbito del derecho familiar, es necesaria la regulación de los múltiples efectos que genera el alquiler de vientre conforme a su naturaleza, características y peculiaridades propias, con especial cuidado en el interés superior del menor, los derechos humanos de la mujer y en aquellos que impactan en los derechos inherentes a la persona, entre los cuales sobresalen la vida, la dignidad humana, así como la intimidad personal y familiar.

\section{BIBLIOGRAFÍA}

Álvarez de Lara, Rosa María et al., Diccionario de derecho civil y de familia, México, Porrúa, 2004.

Biblia, Madrid, Liturgia, 1985.

Boladeras Cucurella, Margarita, Bioética, Madrid, Síntesis, 1999.

BREnA SESMA, Ingrid, "La gestación subrogada ¿una nueva figura del derecho de familia?”, en Brena Sesma, Ingrid (coord.), Reproducción asistida, México, UNAM, 2012, pp. 139-161.

BRena Sesma, Ingrid, "Algunas consideraciones en torno al derecho a la reproducción por medio de inseminación artificial”, en Boletín Mexicano de Derecho Comparado, México, nueva serie, XXVIII, 82 (enero-abril de 1995), pp. 71-89. 
Carcaba Fernández, María, Los problemas jurídicos planteados por las nuevas técnicas de procreación, Barcelona, Bosch, 1995.

CARrillo B., Vanesa L., "La falta de validez del contrato para maternidad subrogada o sustituta, de acuerdo a las normas vigentes en Panamá, sobre contratos civiles, filiación y derecho de menores", en Anuario de Derecho, Madrid, XXVIII, 34-35 (2005-2006), pp. 105-144.

Corral TAlciani, Hernán, "Maternidad subrogada: sobre la pretensión de formalizar la filiación perseguida mediante la adopción o la recepción de su práctica en el extranjero", en Cristián Lepin Molina (coord.), Técnicas de reproducción humana asistida. Desafios del siglo XXI: una mirada transdisciplinaria, Chile, AbeledoPerrot-Thomson Reuters, 2013, pp.165-188.

Coulanges, Fustel de., La ciudad antigua, 9 ed., México, Porrúa, 1994.

Cumpiano Alfonso, Flavio, “¿Bebés a la orden? Consideraciones ético-jurídicas de la maternidad subrogada”, en Revista del Colegio de Abogados de Puerto Rico, Puerto Rico 56, 1 (enero-marzo de 1995), pp. 77-95.

ChIAPERo, Silvana Maria, Maternidad subrogada. Esterilidad. Derecho a la procreación. Nuevas técnicas. Protección del embrión extracorpóreo. Filiación. El contrato de gestión por otro. Efectos de la nulidad, Argentina, Astrea, 2012.

FARnós Amorós, Esther, Consentimiento a la reproducción asistida. Crisis de pareja y disposición de embriones, Barcelona, Atelier, 2011.

Gómez de la Torre Vargas, Maricruz, La fecundación in vitro y la filiación, Chile, Editorial Jurídica de Chile, 1993.

Hernández Ramírez Adriana y Santiago Figueroa, José Luis, "Ley de Maternidad Subrogada en el Distrito Federal", en Boletín Mexicano de Derecho Comparado, México, nueva serie, XLIV, 132 (septiembre-diciembre de 2011), pp.1335-1348.

Lara Peinado, Federico, Código de Hammurabi, Madrid, Editora Nacional, 1982,

Lema Añón, Carlos, Reproducción, poder y derecho. Ensayo filosófico-jurídico sobre las técnicas de reproducción asistida, Madrid, Trotta, 1999.

LOYARTe, Dolores y Rotonda, Adriana, Procreación humana artificial; un desafio bioético, Buenos Aires, Depalma, 1995.

MarTínez, Stella Maris, Manipulación genética y derecho penal, Buenos Aires, Universidad, 1994.

Martínez-Pereda Rodríguez, José Manuel y Massigoge Benegiu, J. M., La maternidad portadora subrogada o de encargo en el derecho español, Madrid, Dykinson, 1994.

Ortiz SÁnchez, Ricardo, "Gestación subrogada”, en Revista Jurídica de Puerto Rico, Puerto Rico 76, 4 (2007), pp. 1197-1225.

SoTo LAMADRID, Miguel Ángel, Biogenética, filiación y delito. La fecundación artificial y la experimentación genética ante el derecho, Argentina, Astrea, 1990. 
VALDIVIEZo García, Marcelo, "La ingeniería genética y la maternidad asistida", en Revista Jurídica. Órgano Oficial del Colegio de Abogados de la Libertad, Perú, 134 (enero 1996-julio 1999), pp.129-145.

VIDAl MARTínez, Jaime, Las nuevas formas de reproducción humana. Estudio desde la perspectiva del derecho civil español, Madrid, 1988.

VIDELA, Mirta, Los derechos humanos en la bioética, Buenos Aires, 1999.

\section{NORMATIVIDAD}

Constitución Política de los Estados Unidos Mexicanos, en http://www.diputados. gob.mx/LeyesBiblio/ref/cpeum.htm, fecha de consulta: 15 de diciembre de 2014 .

Convención de los Derechos del Niño, en http://www.cndh.org.mx/sites/all/fientes/Documentos/Programas/Discapacidad/Conv_DNi\%X3\%B1o.pdf, fecha de consulta: 3 de diciembre de 2014 .

Programa de Acción de la Conferencia Internacional sobre Población y Desarrollo, en http://www.un.org/popin/icpd/conference/offspa/sconf13.html, fecha de consulta: 12 de diciembre de 2014.

Código Civil para el Distrito Federal, en http://www.aldf.gob.mx/archivo-2fd95a8c6ed782165d78dc80b1, fecha de consulta: 20 de diciembre de 2014.

Código Civil del estado de Querétaro, en http:/ /www.legislaturaqueretaro.gob.mx/ repositorios/10.pdf, fecha de consulta: 22 de diciembre de 2014.

Código Civil para el estado de Tabasco, en http://www.congresotabasco.gob.mx/ LX/trabajo_legislativo/pdfs/codigos/Codigo_Civil_Tabasco.pdf, fecha de Consulta: 23 de diciembre de 2014 .

Código Civil para el estado libre y soberano de Morelos, en http://instituto.congresomorelos.gob.mx/nuestras_leyes/pdf/codigos/Codigo_CIVILEM.pdf, fecha de consulta: 17 de diciembre de 2014 .

Código Familiar para el estado libre y soberano de Morelos, en http://instituto. congresomorelos.gob.mx/nuestras_leyes/pdf/codigos/Codigo_FAMILIAREM. pdf, fecha de consulta: 17 de diciembre de 2014 .

Nuevo Código Civil para el estado de Colima, en http://www.congresocol. gob.mx/ leyes/codigo_civil.pdf, fecha de consulta: 25 de diciembre de 2014.

Código Civil para el estado libre y soberano de Baja California Sur, en http:// ww.cbcs.gob.mx/index.php?option=com_content\&id=2097\&Itemid=154PARA, fecha de consulta: 13 de diciembre de 2014.

Código Civil del estado de México, en http://www.infosap.gob.mx/leyes_y_codigos. html, fecha de consulta 19 de diciembre de 2014. 
Código de Familia del estado de Zacatecas, en http://docs.mexico.justia.com. s3.amaznaws.com/estatales/zacatecas/codigo-familiar-del-estado-de-zacatecas.pdf. fecha de consulta: 21 de diciembre de 2014.

Código Familiar para el estado de Michoacán de Ocampo, en http://micrositios. dif.gob.mx/pdmf/files/2014/10/C\%C3\%93DIGO-FAMILIAR-PARA-EL-ESTADO-DEMICHOACAN\%C3\%81N-DE-OCAMPO.pdf, fecha de consulta: 20 de diciembre de 2014.

Código Familiar del estado de Sinaloa, en http://www.laipsinaloa.gob.mx/images/stories/ARCHIVOS\%20PUBLICOS/Leyes\%20Estatales\%20Actuales/codigo\%20civil.pdf, fecha de consulta: 26 de diciembre de 2014.

Código Civil para el estado de Coahuila de Zaragoza, en http:/ coahuila.gob.mx/ archivos/pdf/C\%C3\%B3digo\%20Civil\%20para\%20el\%20Estado\%20de $\% 20$ Coahuila.pdf, fecha de consulta: 21 de diciembre de 2014.

Código Familiar para el estado de San Luis Potosí, en http://docs.mexico.justia. com.com.s3.amazonaws.com/estatales/san-luis-potosi/codigo-familiar-parael-estado-de-san-luis-potosi.pdf, fecha de consulta: 19 de diciembre de 2014.

Código de Familia para el estado de Sonora, en http://transparencia.esonora. gob.mx/NR/rdonlyres/954A41CE-2B36-447B-94f6-BE8DD4444253/64550/ CODIGODEFAMILIAPARAELESTADODESONORA.pdf, fecha de consulta: 23 de diciembre de 2014.

Sentencia del Tribunal Supremo alemán, en http://juris.bundesgerichtshof.de/ cgi-bin/rechtsprechung/document.py?Gericht=bgh\&Art=pm\&Datum=2014\&S ort=3\&anz=193\&pos=1\&nr=69759\&linked=bes\&Blank=1\&file=dokument.pdf, fecha de consulta: 26 de diciembre de 2015.

Sentencia del Tribunal Supremo español, en http://www.poderjudicial.es/search/ doAction?action=contentpdf $\&$ databasematch=TS\&reference=7288332\&links= derecho\%20internacional $\% 20$ privado\&optimize $=20150213 \&$ publicinterface $=\mathrm{t}$ rue, fecha de consulta: 25 de diciembre de 2015 . 